\title{
Archipel
}

ARCHIPEL Études interdisciplinaires sur le monde insulindien

$93 \mid 2017$

Varia

\section{Reconciling Indonesian History with 1965 : Facts, Rumours and Stigma}

Francfort, 10, 11, 12 novembre 2016

\section{Rémy Madinier}

\section{(2) OpenEdition \\ Journals}

\section{Édition électronique}

URL : http://journals.openedition.org/archipel/399

DOI : 10.4000/archipel.399

ISSN : 2104-3655

\section{Éditeur}

Association Archipel

Édition imprimée

Date de publication : 6 juin 2017

Pagination : 11-13

ISBN : 978-2-910513-74-0

ISSN : 0044-8613

\section{Référence électronique}

Rémy Madinier, «Reconciling Indonesian History with 1965 : Facts, Rumours and Stigma », Archipel [En ligne], 93 | 2017, mis en ligne le 01 juin 2017, consulté le 15 septembre 2020. URL : http:// journals.openedition.org/archipel/399 


\section{« Reconciling Indonesian History with 1965: Facts, Rumours and Stigma »}

Francfort, 10, 11, 12 novembre 2016

Plus de cinquante ans après les faits, près de vingt ans après la chute de Suharto, la seule véritable démocratie d'Asie du Sud-Est et l'une des rares du monde musulman peine encore - c'est un euphémisme - à étudier sereinement le traumatisme de 1965. Longtemps empêché par la propagande d'un Ordre nouveau dont ces massacres constituaient le péché fondateur, le travail scientifique demeure aujourd'hui encore entravé par une instrumentalisation politique grossière qui hypothèque la tenue de la plupart des conférences sur le sujet en Indonésie. Il convient donc de saluer la tenue, au mois de novembre dernier, à Francfort, du colloque « Reconciling Indonesian History with 1965: Facts, Rumours and Stigma ». Organisé par Elsa Clavé à la Goethe Universität (avec le soutien du Deutsche Forschungsgemeinschaft et du Centre Asie du Sud-Est) cet événement a permis un déplacement sous des cieux plus cléments d'une partie des chercheurs indonésiens travaillant sur la question (où ils constituaient les deux tiers des vingt-cinq intervenants).

L'originalité de cette rencontre scientifique est d'avoir su restituer les évènements de 1965-1966 dans un temps plus long de l'histoire politique, sociale et culturelle du pays permettant une compréhension plus fine des ressorts des massacres et de ses conséquences sur l'Indonésie d'aujourd'hui. Peu de communications sont ainsi revenues sur le déroulé de la répression anticommuniste. Cette mise en perspective selon une optique plus large témoigne à la fois du consensus scientifique désormais établi sur cette question et d'une volonté d'analyser dans toute son historicité un drame qui apparaît de plus en plus comme l'un des évènements majeurs du $\mathrm{XX}^{\mathrm{e}}$ siècle indonésien. 
Les trois premiers panels («Violent events in the Indonesian Communist Party 1926-1965 », "Cultural violence in the 1960's » et "Communism, atheism and religion ») se sont attachés à restituer 1965 dans l'histoire du communisme indonésien depuis les années 1920, en montrant à la fois la nécessité de contextualiser les tensions du début des années 1960 et de remettre en cause le récit simpliste d'un affrontement séculaire. Plusieurs communications ont ainsi démontré que les accusations d'athéisme portées à l'encontre des communistes ne reflétaient pas la variété et la plasticité spirituelles de la plupart de ses membres. Des nuances qui permettent de comprendre les collaborations, parfois étroites, nouées entre le PKI et les forces se revendiquant de l'islam jusqu'à la fin des années 1940. Plusieurs autres intervenants ont insisté sur la dimension culturelle, essentielle à la compréhension tant des prémices du drame que de la longue stigmatisation qui a touché les intellectuels et artistes de la gauche indonésienne depuis. Le panel 4 ( «Land grabbing and the phantom of communism») s'est attaché à un dossier essentiel à l'analyse des enjeux économiques de l'affrontement avec le PKI : celui de la réforme agraire, votée en 1960 et dont la difficile application fut à l'origine de très nombreuses tensions, en particulier à Java. Fondée sur l'étude de documents inédits, les deux communications de ce panel ont montré en particulier que les enjeux fonciers avaient joué un rôle de première importance dans le « ciblage » des victimes de la répression puis avaient pesé sur les processus de réconciliation dans les décennies qui ont suivi. Les deux derniers panels se sont plus attachés à l'étude de la construction mémorielle de l'événement par le régime de l'Ordre nouveau et à la remise en cause à la fois tardive et très progressive de cette version officielle. La construction d'un récit forgé par le pouvoir - et justifiant les massacres - avait débuté dès le premiers jours de la répression. Sa diffusion avait accompagné l'extension des exactions à la plupart des régions de l'Archipel. Dans les années qui ont suivi, le cinéma fut un relais fort efficace pour entretenir cette mémoire institutionnelle de l'événement et justifier la poursuite de la traque d'hypothétiques réseaux communistes dans le pays. À l'inverse, depuis la chute de Suharto, le septième art a été l'un des moyens les plus efficaces de remettre en cause ce récit, encore enseigné dans les écoles, et surtout de toucher un public allant bien au delà des cercles intellectuels et militants (Panel 5 « Film and stigma »). Les panels 6 et 7 ( "The impact on the young generation ») ont montré que l'éviction durable de toute la gauche de la scène politique indonésienne était sans doute l'héritage le plus tangible des dramatiques évènements de 1965 pour les jeunes générations. Alors que la mémoire directe du drame s'estompe (d'autant plus qu'elle a été largement occultée) la stigmatisation du communisme est encore souvent instrumentalisée pour discréditer toute revendication sociale dans l'Archipel. La plupart des mobilisations militantes, en particulier étudiantes, et plus largement l'ensemble du débat intellectuel 
indonésien, se heurtent encore aujourd'hui à un discours mettant en garde la population face au risque d'un retour des tensions mortifères qui précédèrent les évènements du 30 septembre.

Ces interrogations sur la mémoire indonésienne ont enfin conduit à un élargissement international avec des comparaisons avec la manière dont le Cambodge, l'Allemagne et la France ont affronté le souvenir de massacres perpétrés sur son sol (et dans le cas de la France dans ses colonies). La rencontre s'est terminée avec trois témoignages plus personnels : celui de la fille de l'un des généraux assassinés dans la nuit du 30 septembre, celui d'un ancien prisonnier politique et enfin celui d'une enseignante d'histoire confrontée à la difficulté de transmettre, souvent contre la mémoire parentale et contre son administration, une connaissance objective à ses élèves de lycée.

Ponctuée d'évènements bienvenus (exposition de photos et projection de documentaires), riche de discussions informelles, ce colloque, fort bien organisé, a su heureusement témoigner de la rigueur scientifique avec laquelle est conduite ce combat pour la vérité.

RÉMY MADINIER 
